\title{
Platelet Parameters Assessment among Sudanese Pregnant Women with Preeclampsia Attending Wad Medani Obstetrics and Gynecology Teaching Hospital
}

\author{
Ejlal Omer FadlElseed ${ }^{1}$, Khalid Abdelsamea Mohamedahmed ${ }^{1,2 *}$, Aboagala Mustafa \\ Mohamed $^{3}$, Muatez Ibrahim Hassan ${ }^{4}$, Albadawi Abdebagi Talha ${ }^{5}$ \\ 1 Department of Hematology, Faculty of Medical Laboratory Sciences, University of Gezira, Wad Medani, Sudan \\ 2 Department of Immunology, Faculty of Medical Laboratory Sciences, University of Gezira, Wad Medani, Sudan \\ 3 Department of Clinical Chemistry, Faculty of Medical Laboratory Sciences, University of Gezira, Wad Medani, Sudan \\ 4 Department of Clinical Chemistry, Faculty of Medical Laboratory Sciences, Shendi University, Shendi, Sudan \\ 5 Department of Medical Parasitology, Faculty of Medical Laboratory Sciences, University of Gezira, Wad Medani, Sudan
}

\begin{abstract}
*Corresponding Author: Dr. Khalid Abdelsamea Mohamedahmed, Department of Hematology and Immunology, Faculty of Medical Laboratory Science, University of Gezira, Wad Medani, Sudan. ORCID No: 0000-0001-7084-6106, Email: khalid.gu89@gmail.com, Tel: +249114660424
\end{abstract}

Received: July 30, 2021; Accepted: September 18, 2021

\section{Abstract}

Background: Preeclampsia is considered as one of the major health problems associated with pregnancy and one of the causes of maternal mortality. The pathogenesis of preeclampsia associated with platelets activation. Aims and Objectives: The aim of this study was to evaluate the platelets parameters (platelet count and platelet indices) in pregnant women with preeclampsia. Design and Methods: This is a case-control laboratory based study carried out in Wad Medani Obstetrics and Gynecology Teaching Hospital, Gezira State, Sudan from January to November 2020. A total of 50 pregnant women with preeclampsia as cases (32.20 \pm 3.21 years) and 50 normotensive pregnant women as controls (30.68 \pm 2.85 years) were participated in this study. Three $\mathrm{ml}$ of venous blood samples were collected from all participants in $\mathrm{K}_{3}$ EDTA containers. platelets parameters (platelet count and platelet indices) were determined using Mindray BC 3000 Automated Hematology Analyzer. Data were analyzed using SPSS computer program (version 22). Results: The study results showed that the thrombocytopenia account for $56 \%$, all cases with low PCT (100\%). Furthermore the means of PLTs count, PCT and PDW in cases were (144.40 $\pm 31.80 \times 10^{9} / \mathrm{L}, 0.13 \pm 0.03 \%$ and $15.80 \pm 0.45 \mathrm{fl}$ respectively) versus controls $\left(269.40 \pm 72.50 \times 10^{9} / \mathrm{L}, 0.22 \pm 0.05 \%\right.$ and $15.50 \pm 0.29 \mathrm{fl}$ respectively), giving statistically significant differences $(P$ value $=0.000$, 0.003 and 0.022 respectively). The mean of PCT of mild cases was lower than severe cases ( $P$ value $=0.004$ ); but there were no significant differences in PLTs count, MPV and PDW ( $\mathrm{P}$ value $=0.379,0.283$ and 0.075 respectively). Conclusion: The study concluded that platelet count (PLTs count) and plateletcrit (PCT) were significantly decreased in pregnant women with preeclampsia especially; so platelets parameters especially (PLTs count and PCT) should be included for assessing and predication of the risk of severe preeclampsia.

Keywords: Severe preeclampsia, Pregnant women, Platelets count, Platelets count indices, Sudan.

\section{INTRODUCTION}

Preeclampsia (PE) is a serious multi-systemic pregnancy complication affecting between $5-8 \%$ of pregnant women Worldwide ${ }^{[1]}$. Therefore, it is considered as one of the major health problems associated with pregnancy and one of the causes of maternal mortality ${ }^{[2-3]}$. The prevalence of $\mathrm{PE}$ in developing countries ranges from $1.8 \%$ to $16.7 \%$ [4]. Preeclampsia has been a major cause of poor result in pregnancy and the category "hypertensive diseases of pregnancy" and is a leading cause of maternity death in Africa [5]. The pathogenesis of PE remains unknown, and the many theories related to the etiology of PE pose great challenges for 
future investigation. The abnormal invasion of placenta and the release of placenta-derived adverse factors during the first trimester are thought to be the main cause of the extensive damage to the maternal endothelium and systemic inflammatory response involving many systems and organs in late pregnancy [6]. Although the causes of PE are completely unknown, one of the responsible mechanisms is thought to be activation of inflammatory systems with predominant involvement of cytokines and chemokines. However, there is an ongoing debate about whether inflammatory system hyperactivity indeed exists during PE and if available data are sufficient for justification of broad anti-immune system treatment strategies ${ }^{[7-}$ ${ }^{8]}$. $\mathrm{PE}$ is characterized by hypertension (blood pressure $>140 / 90$ $\mathrm{mmHg}$ ), proteinuria (>0.3 $\mathrm{g} / \mathrm{d}$ ), edema and other symptoms and may begin as early as the 20th gestational week and last for 6 weeks after delivery [9].

Platelets are critical to normal homeostasis and help limit blood loss following vascular injury. In pregnancy, they become increasingly important in preventing excessive bleeding during and immediately following birth [10]. A growing body of evidence demonstrating that inflammation in microvasculature plays major role in the pathogenesis of preeclampsia. Although circulating platelets are in rested state, when they are exposed to soluble mediators or micro-particles in the inflamed vasculature as in preeclampsia, platelet are activated by engagement of the mediators on surface receptors. Upon activation, platelet degranulated some soluble and adhesion molecules [11]. Several studies suggested that when platelets were activated and become larger in size which causes increased platelet indices such as MPV, PDW and PCT [12].

\section{MATERIALS AND METHODS}

The study was designed as case control laboratory based study, carried out at Wad Medani Obstetrics and Gynecology Teaching Hospital, Gezira State, Sudan during period from January to October 2020. The samples were collected randomly from 100 females (50 females with preeclampsia as cases and 50 normal healthy pregnant females as controls) according to inclusion and exclusion criteria.

All study procedures were approved by the Researches and Ethics Committees (REC) of Ministry of Health, Gezira State and Faculty of Medical Laboratory Sciences, University of Gezira, Sudan. Informed consent was written from each participants.

A $2.5 \mathrm{ml}$ venous blood sample was collected by clean venipuncture technique in $\mathrm{K}_{2}$ EDTA anticoagulant containers from each participants [13]. Thin blood film was prepared immediately. Platelets parameters (platelets count and indices) were measured using the Mindray BC 3000 Plus Cell Counter (Sysmex, Kobe, Japan). The platelets count was confirmed and assessed using stained thin blood film. The data were analyzed using statistical package for social sciences (SPSS) computer program (Version 22.0).

\section{RESULTS}

50 Sudanese females with preeclampsia (mean age $32.20 \pm$ 3.21 years) and 50 normal healthy pregnant Sudanese females (mean age $30.68 \pm 2.85$ years) were participated in this study. Most case in age group more than 30 years (58\%), Most case in third trimester of pregnancy $(76 \%)$ and had no family history of preeclampsia (72\%); $50 \%$ of cases had severe preeclampsia (Table 1).
Table 1: Demographic characteristics of study participants.

\begin{tabular}{|l|l|l|}
\hline Factors & Cases (N = 50) & Control (N = 50) \\
\hline Age (years) (Mean \pm SD) & $32.20 \pm 3.21$ & $30.68 \pm 2.85$ \\
\hline Age group (years) & & \\
\hline$\leq 30$ years & $22(44 \%)$ & $27(54 \%)$ \\
\hline$<30$ years & $28(58 \%)$ & $23(46 \%)$ \\
\hline Weight & $71.10 \pm 5.70$ & $67.84 \pm 5.63$ \\
\hline Trimester & & \\
\hline Second & $12(24 \%)$ & $5(10 \%)$ \\
\hline Third & $38(76 \%)$ & $45(90 \%)$ \\
\hline Preeclampsia severity & & \\
\hline Mild & $25(50 \%)$ & \\
\hline Severe & $25(50 \%)$ & \\
\hline Family history & & \\
\hline Yes & $14(28 \%)$ & \\
\hline No & $36(72 \%)$ & \\
\hline
\end{tabular}

On the other hand, the thrombocytopenia account for $56 \%$, all cases with low PCT (100\%), most cases with normal MPV (98\%) and PDW (100\%) (Figure 1).

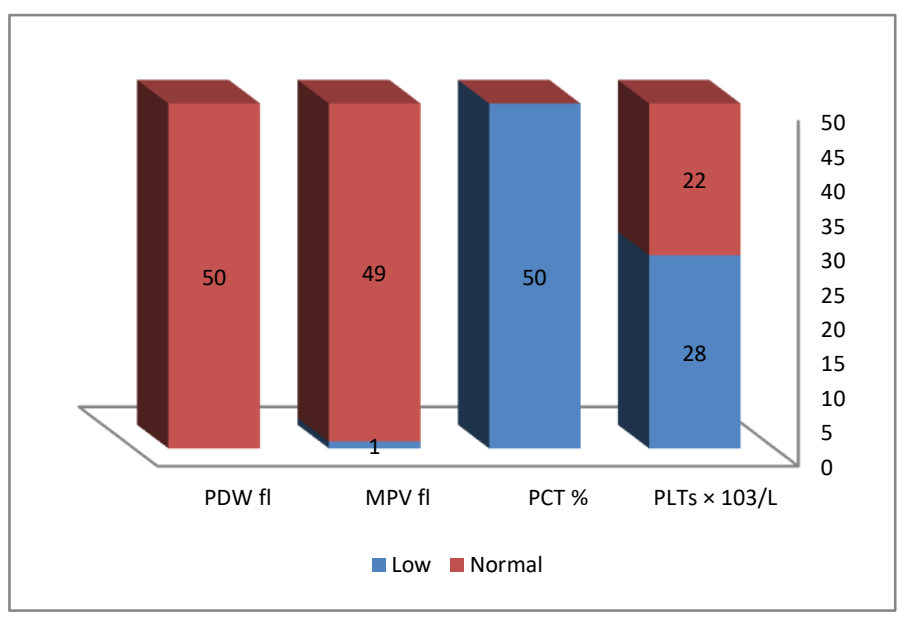

Figure 1: Frequency of platelets parameters among cases.

The means of PLTs count, PCT and PDW in cases were (144.40 $\pm 31.80 \times 10^{9} / \mathrm{L}, 0.13 \pm 0.03 \%$ and $15.80 \pm 0.45 \mathrm{fl}$ respectively) versus controls $(269.40 \pm 72.50 \times 10 \% / \mathrm{L}, 0.22 \pm 0.05 \%$ and 15.50 $\pm 0.29 \mathrm{fl}$ respectively), giving statistically significant differences ( $P$ value $=0.000,0.003$ and 0.022 respectively); while there was no significant difference in MPV between them ( $P$ value 0.884 ) (Table 2).

Table 2: Comparison of platelets parameters between cases and control.

\begin{tabular}{|l|l|l|l|}
\hline Parameters & $\begin{array}{l}\text { Cases (N=50) } \\
(\text { Mean } \pm \text { SD) }\end{array}$ & $\begin{array}{l}\text { Controls (N=50) } \\
(\text { Mean } \pm \text { SD) }\end{array}$ & P value * $^{*}$ \\
\hline PLTs count $\times \mathbf{1 0}^{\mathbf{9}} / \mathbf{L}$ & $144.40 \pm 31.80$ & $269.40 \pm 72.50$ & $\mathbf{0 . 0 0 0}$ \\
\hline PCT \% & $0.13 \pm 0.03$ & $0.22 \pm 0.05$ & $\mathbf{0 . 0 0 3}$ \\
\hline MPV fl & $9.30 \pm 0.70$ & $8.30 \pm 0.72$ & 0.884 \\
\hline PDW fl & $15.80 \pm 0.45$ & $15.50 \pm 0.29$ & $\mathbf{0 . 0 2 2}$ \\
\hline
\end{tabular}


The mean of PCT of mild cases was $(0.15 \pm 0.02 \%)$ versus controls $(0.12 \pm 0.03 \%)(P$ value $=0.004)$; but there were no significant differences in PLTs count, MPV and PDW $(P$ value $=$ $0.379,0.283$ and 0.075 respectively) (Table 3 ).

Table 3: Comparison of platelets parameters between Mild and severe preeclampsia.

\begin{tabular}{|l|l|l|l|}
\hline Parameters & $\begin{array}{l}\text { Mild (N=25) } \\
(\text { Mean } \pm \text { SD) }\end{array}$ & $\begin{array}{l}\text { Severe (N=25) } \\
\text { (Mean } \pm \text { SD) }\end{array}$ & P value * $^{*}$ \\
\hline PLTs count $\times \mathbf{1 0} / \mathbf{L}$ & $166.60 \pm 18.30$ & $122.30 \pm 26.80$ & 0.379 \\
\hline PCT \% & $0.15 \pm 0.02$ & $0.12 \pm 0.03$ & $\mathbf{0 . 0 0 4}$ \\
\hline MPV fl & $9.05 \pm 0.70$ & $9.70 \pm 0.55$ & 0.283 \\
\hline PDW fl & $15.70 \pm 0.34$ & $16.00 \pm 0.50$ & 0.075 \\
\hline
\end{tabular}

There were no significant differences in PLTs count, PCT, MPV and PDW between trimester among cases ( $P$ value $=0.588$, $0.171,0.185$ and 0.414 respectively) (Table 4$)$.

Table 4: Comparison of platelets parameters between second and third trimester.

\begin{tabular}{|l|l|l|l|}
\hline Parameters & $\begin{array}{l}\mathbf{2}^{\text {nd }} \text { trimester } \\
(\mathbf{N}=\mathbf{1 2}) \\
(\text { Mean } \pm \text { SD })\end{array}$ & $\begin{array}{l}\mathbf{3}^{\text {rd }} \text { trimester } \\
(\mathbf{N}=\mathbf{3 8}) \\
(\text { Mean } \pm \text { SD })\end{array}$ & P value $^{*}$ \\
\hline PLTs count $\times \mathbf{1 0}^{\mathbf{9}} / \mathbf{L}$ & $149.80 \pm 26.80$ & $142.70 \pm 33.40$ & 0.588 \\
\hline PCT \% & $0.14 \pm 0.02$ & $0.13 \pm 0.03$ & 0.171 \\
\hline MPV fl & $9.30 \pm 0.82$ & $9.30 \pm 0.68$ & 0.185 \\
\hline PDW fl & $15.80 \pm 0.41$ & $15.90 \pm 0.46$ & 0.414 \\
\hline
\end{tabular}

\section{DISCUSSION}

Preeclampsia (PE) is a multisystem disorder of unknown cause, it is characterized by abnormal vascular response that is associated with increased systemic vascular resistance, enhanced platelet aggregation, activation of the coagulation system and endothelial cell dysfunction [6]. Complete blood count $(\mathrm{CBC})$ parameters including platelet count and platelet indices such as MPV, PDW and PCT are widely available and are less cost-effective. However, in daily practice, most physicians consider only $\mathrm{CBC}$ parameters thus neglecting other parameters like platelet indices ${ }^{[14]}$.

This is a case control hospital based study carried out in Wad Medani Obstetrics and Gynecology Teaching Hospital, Gezira State, Sudan from January to October 2020 to evaluate the platelet count and platelet indices (MPV, PCT and PDW) among preeclampsic women. 50 Sudanese pregnant women with preeclampsia (mean age $32.20 \pm 3.21$ years) and 50 normal healthy pregnant women (mean age $30.68 \pm 2.85$ years) were randomly selected according to inclusion and exclusion criteria.

The study results showed there were significant differences between cases and controls in platelets count ( $P$ value $=0.000)$, PDW $(P$ value $=0.022)$, and PCT $(P$ value $=0.003)$. This study results similar to studies done in United Kingdom [15], Egypt [16], India [17-18], Brazil in 2013 stated that Lower PLT count and PCT were observed in PE comparing to normal pregnant and to nonpregnant women with $P$ value $<0.001{ }^{[19]}$, and in Sudan that revealed that among 87 total pregnant women, 37 were preeclamptic pregnant women, and there were significant differences in the platelets indices of MPV, PDW, and PCT among the study group [20]. The preeclampsia associated vascular changes which lead to platelet consumption in repair of vessel damage, contact of platelets with the injured endothelium activates the coagulation system, which can increase both consumption and bone marrow production of platelet, enhance thrombopoiesis produce younger platelet which are larger than older platelet. There was slightly increased in mean MPV of cases but not significant difference when compare with case $(P$ value $=0.283$ ). This result agrees with study done in Egypt by Ahmed et al., [16]. There was slightly increased in means MPV and PDW of cases, this result consistence with study done by Kaito et al., and suggested causes due to hyper-destruction of platelet increases MPV and PDW, because the younger platelet were larger than old platelet which lead to increase in MPV [14]. The study results disagree with study done in Turkey which found no significant differences between patient with preeclampsia and health pregnant, which take 50 cases and 50 controls and compare between them [21]. There was significant difference between mild and severe preeclampsia in PCT (P value $=0.004$ ) due to lower platelet count in severe preeclampsia more than mild preeclampsia, but there were no significant differences in PLT count, MPV and PDW. Sontas et al, revealed that PCT was found to be associated with the severity of PE when it was compared with mild stage ${ }^{[22]}$. This study disagree with Study done by Yayuzcan et al, that reported PCT was no difference between mild and severe PS [21] and agree with Neiger and Contag observed no significant difference in platelet count between mild and severe pre-eclamptic cases ${ }^{[15]}$. There were no significant differences in platelets parameters according to trimester.

\section{CONCLUSION}

The study concluded that platelet count (PLTs count) and plateletcrit (PCT) were significantly decreased in pregnant women with preeclampsia especially; so platelets parameters especially (PLTs count and PCT) should be included for assessing and predication of the risk of severe preeclampsia.

\section{Conflict of Interest Statement}

The authors declare that they have no competing interests.

\section{Author Contributions}

All authors contributed to conception of research, the data analysis and manuscript writing. All authors have approved the final manuscript.

\section{Acknowledgements}

Wad Medani Obstetrics and Gynecology Teaching Hospital and Faculty of Medical Laboratory Sciences, University of Gezira were thanked for helping.

\section{REFERENCES}

1. Sibai B, Dekker G, Kupferminc M. Preeclampsia. Lancet. 2005; 365(9461):785-799.

2. Khan K, Wojdyla D, Say L, Gulmezoglu A, Van LP. WHO analysis of causes of maternal death: a systemic review. BJOG. 2006; 367(9516):1066-1074.

3. Duley L. The global impact of pre-eclampsia and eclampsia. JSemin Perinatol. 2009; 33(3):130-137.

4. Gsungbade K, Ige O. Public Health Perspectives of Preeclampsia in Developing. 2011; 3(16):87.

5. Nakimuli A, Chazara O, Byamugisha J, Elliott A, Kaleebu P, et al. Pregnancy, parturition and preeclampsia in women of African ancestry. Am J Obstet Gynecol. 2013; 21(6):510-520.

6. Staff A, Benton S, Von Dadelszen P, Roberts J, Taylor R, et al. 
Redefining Preeclampsia using placenta derived biomarkers. Hypertension.2013; 61(5):932-942.

7. Lamarca B. The role of immune activation in contributing to vascular dysfunction and the pathophysiology of hypertension during preeclampsia. Minerva Ginecol. 2010; 62(2):105-120.

8. Reslan O, Khalil R. Molecular and vascular targets in the pathogenesis and management of the hypertension associated with preeclampsia. Cardiovasc Hematol Agents Med Chem. 2010; 8(4):204-226.

9. Al-Jameil N, Aziz KF, Fareed KM, Tabassum H. A Brief Overview of Preeclampsia. J Clin Med Res. 2014; 6(1):1-7.

10. Vladareanu $\mathrm{A}$, Andrei $\mathrm{C}$, Onisai $\mathrm{M}$, Vasilache $\mathrm{V}$, Bumbea $\mathrm{H}$, et al. The endothelial-platelet dysfunction in preeclampsia. Med-A $J$ of C. 2007; 2(3):214-221.

11. Steegers E, Von Dadelszen P, Duvkot J, Pijnenborg R. Preeclampsia. Dental and Med Sci. 2010; 376(9741):631-644.

12. Vagdatli E, Gounari E, Lazaridou E, Katsibourlia E, Tsikopoulou $\mathrm{F}$, et al. Platelet distribution width: a simple, practical and specific marker of activation of coagulation. Hippokratia. 2010; 14(1):2832.

13. Bain B, Bates I, Laffan M, Lewis S. Dacie and Lewis practical haematology. ( $11^{\text {th }}$ edition): Churchill Livingstone, London: 2011; pp 37-38.

14. Kaito K, Otsubo H, Usui N, Yoshida M, Tanno J, et al. Platelet size deviation width, platelet large cell ratio, and mean platelet volume have sufficient sensitivity and specificity in the diagnosis of immune thrombocytopenia. $\mathrm{Br} J$ of Haematology. 2005; 128(5):698-702.

15. Neiger R, Contag S, Coustan D. Preeclampsia effect on platelet count. Am J Perinatol. 1992; 5(6):378-380.

16. Ahmed $Y$, van Iddekinge $B$, Paul $C$, Sullivan $M$, Elder $M$. Retrospective analysis of platelet numbers and volumes in normal pregnancy and in pre-eclampsia. An International $J$ of Gyn Obs. 1993; 100(3): 216-220.

17. Sultana R, Karim S, Atia F, Ferdousi S, Ahmed S. Platelet Count In Preeclampsia. J. Dhaka National Med. Coll. Hos. 2012; 18(02):24-26.

18. Amita K, Nithin K, Shobha S, Shankar V. The role of platelet parameters as a biomarker in the diagnosis and in predicting the severity of preeclampsia. Indian J. Pathol Oncol. 2015; 2(2):5760.

19. Freitas L, Alpoim P, Komatsuzaki F, Carvalho M, Dusse L. Preeclampsia: are platelet count and indices useful for its prognostic? Hematology. 2013; 18(6):360-364.

20. Abass A, Abdalla R, Omer I, Ahmed S, Khalid A, et al. Evaluation of Platelets Count and Indices in Pre- Eclampsia Compared to Normal Pregnancies. IOSR-SDMS. 2016; 15(7):5-8.

21. Yavuzcan A, Caglar M, UstunY, DilbazN, Ozdemir I, et al. Mean Platelet Volume, Neutrophil-Lymphocyte Ratio and PlateletLymphocyte Ratio in Severe Pre-eclampsia.Journal J of Dental and Med Sci. 2014; 85(3):197-203.

22. Santos S, dos E, José M. Measurement of platelet parameters in normal and preeclamptic pregnant women. Rev Bras GynecolObstet. 2004; 26:201-206. 